\title{
Phytosome as a Novel Biomedicine: A Microencapsulated Drug Delivery System
}

\author{
Harshal Ashok Pawar ${ }^{1 *}$ and Bhagyashree Dilip Bhangale ${ }^{2}$
}

${ }^{1}$ Assistant Professor and HOD (Quality Assurance), Dr. L. H. Hiranandani College of Pharmacy, Ulhasnagar, Maharashtra, India ${ }^{2}$ Research Scholar (M.Pharm.), Dr. L. H. Hiranandani College of Pharmacy, Ulhasnagar, Maharashtra, India

\begin{abstract}
The term "phyto" means plant while "some" means cell-like. Phytosome is a novel emerging technique applied to phyto-pharmaceutical which contains phytoconstituents of herbal extract surrounds and bound by lipid. Most of bioactive constituents of phyto-medicine are water soluble compounds like flavonoids. Because of water solubility and lipophilic outer layer, phytosome shows better absorption, hence produces better bioavailability than the conventional herbal extracts. Because of their improved pharmacological and pharmacokinetic properties, phytosome are used to treat acute and chronic liver diseases and therapeutically used as dietary supplements. The current review highlights key findings of recent research work conducted on phytosomes with our own viewpoints which can give the new directions and advancements to herbal dosage forms and the technical aspects of phyto-phospholipid formulations to face the future challenges.
\end{abstract}

Keywords: Drug delivery; Phytosome; Phosphatidylcholine (PC); Phospholipid complex; Bioavailability; Flavonoids

\section{Introduction}

Novel drug delivery system aims to deliver the drug at a rate directed by the needs of the body during the period of the treatment, and channel the active entity to the site of action. A number of novel drug delivery systems have been emerged encompassing various routes of administration, to achieve controlled and targeted drug delivery by encapsulation of the drug in systemic circulation which reduces the tonicity and selective uptake of drug. Consequently a number of vesicular drug delivery systems such as liposomes, niosomes, transferosomes and pharmacosomes were developed. Advances have since been made in the area of vesicular drug delivery, leading to development of systems that allow drug targeting, and the sustained or controlled release of conventional medicines [1].

Since ancient times the therapeutic uses of traditional medicines and phyto-medicines have proved very popular for health maintenance by various means. The advancement in the field of herbal drug delivery started recently with the aim to manage human diseases efficiently [2]. Every nation is seeking health care beyond the traditional boundaries of modern medicine; turning to self medication in the form of herbal remedies. Most of bioactive constituents of phyto-medicines are water soluble molecules (e.g. Phenolics, glycosides, flavonoids etc.). However, water soluble phytoconstituents are limited in their effectiveness because they are poorly absorbed when taken orally or when applied topically. Many approaches have been developed to improve the oral bioavailability, such as inclusion of solubility and bio availability enhancer, structural modification and entrapment with the lipophilic carriers and thus extensive research in the field of herbal drug delivery systems as a means of improving the therapeutic indices of drugs is inevitable. The use of formulation technology to deliver herbal products and drugs by improved absorption and, as a consequence, produce better results than those obtained by conventional herbal extracts. Phytosome are not liposome; structurally the two are distinctly different. The phytosome is a unit of a few molecules bonded together, while liposome is an aggregate of many phospholipid molecules and encloses other phyto-active molecules but without specially bonding to them [3]. Phytosome technology is a breakthrough model for marked enhancement of bioavailability, significantly greater clinical benefit, assured delivery to the tissues, without compromising nutrient safety [4]. Some of the differentiating characteristics between phytosome and liposome are summarized in (Table 1).

\section{Novel Vesicular Drug Delivery System}

Novel vesicular drug delivery systems aim to deliver the drug at a rate directed by need of body during the period of treatment, and channel the active entity to the site of action. A number of novel vesicular drug delivery systems have been emerged encompassing various routes of administration, to achieve targeted and controlled drug delivery. Targeted drug delivery is a mode of delivering the therapeutic agent to the tissues of interest while reducing the relative concentration of therapeutic agent in remaining tissues which improves the therapeutic efficacy and reduces the side effects. Drug targeting means the delivery of drugs to receptor, organs or any other specific part of body to which one wishes to deliver the entire drug. Few newly developed novel vesicular drug delivery systems are summarized in (Table 2) [5-7].

\section{Phytosome}

The term 'Phyto' means plant while 'Some' means cell-like. Phytosome is vesicular drug delivery system in which phytoconstituents of herb extract surround and bound by lipid (one phyto-constituent molecule linked with at least one phospholipid molecule). Phytosome protect valuable component of herbal extract from destruction by digestive secretion and gut bacteria and because of which they shows better absorption which produces better bioavailability and improved

*Corresponding author: Harshal Ashok Pawar, Assistant Professor and Head of Department (Quality Assurance), Dr. L. H. Hiranandani College of Pharmacy, Smt. CHM Campus, Opp. Ulhasnagar Railway Station, Ulhasnagar-421003, Maharashtra, India, Tel: +91-8097148638; E-mail: harshal.dlhhcop@gmail.com

Received December 14, 2014; Accepted December 30, 2014; Published January 05, 2015

Citation: Pawar HA, Bhangale BD (2015) Phytosome as a Novel Biomedicine: A Microencapsulated Drug Delivery System. J Bioanal Biomed 7: 006-012. doi:10.4172/1948-593X.1000116

Copyright: @ 2015 Pawar HA, et al. This is an open-access article distributed unde the terms of the Creative Commons Attribution License, which permits unrestricted use, distribution, and reproduction in any medium, provided the original author and source are credited. 
Citation: Pawar HA, Bhangale BD (2015) Phytosome as a Novel Biomedicine: A Microencapsulated Drug Delivery System. J Bioanal Biomed 7: 006012. doi:10.4172/1948-593X.1000116

\begin{tabular}{|l|l|l|l|}
\hline S. No. & Property & Phytosome & Riposome \\
\hline 1 & Bonding & It is unit of few molecules bonded together & $\begin{array}{l}\text { It is an aggregate of many phospholipid molecules } \\
\text { that encloses other phytoactive molecules without } \\
\text { specifically bonding to them. }\end{array}$ \\
\hline 2 & Bioavailability and Absorption & It has much better bioavailability and absorption. & $\begin{array}{l}\text { Its bioavailability and absorption is lesser than } \\
\text { phytosome. }\end{array}$ \\
\hline 3 & Arrangement of molecules & $\begin{array}{l}\text { In phytosome, phospholipid (PC) and an individual } \\
\text { phytoconstituent are present in 1:1 or 2:1 ratio } \\
\text { depending on the substance. }\end{array}$ & $\begin{array}{l}\text { liposphatidylcholine molecules surround the water } \\
\text { soluble molecule. }\end{array}$ \\
\hline
\end{tabular}

Table 1: Difference between phytosome and liposomes.

\begin{tabular}{|c|c|c|}
\hline Vesicular system & Description & Application \\
\hline Aquasomes & $\begin{array}{l}\text { These are spherical } 60-300 \mathrm{~nm} \text { particles used for drug and antigen delivery. The particle core is composed of } \\
\text { noncrystalline calcium phosphate (ceramic diamond) and is covered by a polyhydroxyl oligomeric film }\end{array}$ & $\begin{array}{l}\text { Specific targeting, molecular } \\
\text { shielding }\end{array}$ \\
\hline Archaeosomes & Vesicles composed of glycerolipids of archaea with potent adjuvant activity & Poor adjuvant activity \\
\hline Colloidosomes & $\begin{array}{l}\text { These are solid microcapsules formed by the self assembly of colloidal particles at the interface of emulsion } \\
\text { droplets and they are also hollow, elastic shells whose permeability and elasticity can be precisely controlled. }\end{array}$ & Drug targeting \\
\hline Cryptosomes & $\begin{array}{l}\text { Lipid vesicle with surface coat composed of PC and of suitable polyoxyethylene derivative of phosphatidyl } \\
\text { ethanolamine }\end{array}$ & Ligand mediated drug delivery \\
\hline Cubosomes & $\begin{array}{l}\text { Cubosomes are bi-continuous cubic phases, consisting of two separate, continuous, but non intersecting } \\
\text { hydrophilic regions divided by a lipid layer that is contorted into a periodic minimal surface with zero average } \\
\text { curvature. }\end{array}$ & Drug targeting \\
\hline Discosomes & Niosomes coupled with non-ionic surfactants & Ligand mediated drug targeting \\
\hline Emulsosomes & Nanosized lipid particles consisted of lipid assembly and a polar group & $\begin{array}{l}\text { Parenteral delivery of poorly water } \\
\text { soluble drugs }\end{array}$ \\
\hline Enzymosomes & The enzyme covalently immobilized to the surface of liposomes & Targeted delivery to tumour cell \\
\hline Erythrosomes & $\begin{array}{l}\text { Liposomal system in which chemically cross-linked human erythrocytes cytoskeletons are used as to which a lipid } \\
\text { bilayer is coated }\end{array}$ & $\begin{array}{l}\text { Targeting of macromolecular } \\
\text { drugs }\end{array}$ \\
\hline Genosomes & Artificial macromolecular complex for functional gene transfer & Cell specific gene transfer \\
\hline Hemosomes & Haemoglobin containing liposomes prepare by immobilizing haemoglobin with polymerizable phospholipid & $\begin{array}{l}\text { High capacity oxygen carrying } \\
\text { system }\end{array}$ \\
\hline Photosomes & $\begin{array}{l}\text { Photolyase encapsulated in liposomes, which release the contents by photo triggered charges in membrane } \\
\text { permeability characteristics. }\end{array}$ & Photodynamic therapy \\
\hline Protosomes & High molecular weight multi subunit enzyme complexes with catalytic activity & $\begin{array}{l}\text { Better catalytic activity turnover } \\
\text { than non associated enzymes }\end{array}$ \\
\hline Ufasomes & $\begin{array}{l}\text { Vesicles enclosed by fatty acids obtained by long chain fatty acids by mechanical agitation of evaporated film in } \\
\text { the presence of buffer solution }\end{array}$ & Ligand mediated drug targeting \\
\hline Vesosomes & Nested bilayer composed of bilayers enclosing an aqueous core which contains unilamellar vesicle & $\begin{array}{l}\text { Multiple compartment of } \\
\text { Vesosomes give better protection } \\
\text { to the interior content of serum }\end{array}$ \\
\hline Virosomes & Liposomes spiked with virus glycoprotein's, incorporated in the liposomal bilayer based on retrovirus based lipids & Immunological adjuvant \\
\hline
\end{tabular}

Table 2: Emerging "Somes" and their Applications.

pharmacological and pharmacokinetic parameters than conventional herbal extract. The advantages and disadvantage of phytosomes are summarized below.

\section{Advantages}

a) There is a dramatic enhancement of the bioavailability of botanical extracts due to their complexation with phospholipid and improved absorption in the intestinal tract.

b) They permeate the non-lipophilic botanical extract to allow better absorption from the intestinal lumen, which is otherwise not possible [8].

c) The formulation of Phytosome is safe and the components have all been approved for pharmaceutical and cosmetic use.

d) They have been used to deliver liver protecting flavonoids because they can be made easily bioavailable by phytosomes. In addition to this, Phosphatidylcholine is also hepatoprotective and so provides a synergistic effect for liver protection [9].

e) This technology offers cost effective delivery of phytoconstituents and synergistic benefits when used as functional cosmetics to protect the skin against exogenous or endogenous hazards in normal as well as stressful environmental conditions [10].

f) They can be also used for enhanced permeation of drug through skin for transdermal and dermal delivery [11].

g) These are platform for the delivery of large and diverse group of drugs (peptides, protein molecules).

h) The vesicular system is passive, non-invasive and is available for immediate commercialization [11].

i) Phosphatidylcholine, an essential part of the cell membrane used in phytosome technology, acts as a carrier and also nourishes the skin [10].

j) There is no problem with drug entrapment during formulation preparation.

k) Also, the entrapment efficiency is high and moreover predetermined; because the drug itself forms vesicles after conjugation with lipid.

1) They offer a better stability profile because chemical 
bonds are formed between the phosphatidylcholine molecules and Phytoconstituents.

$\mathrm{m})$ The dose requirement is reduced due to improved absorption of the main constituent. They can also be given in smaller quantities to achieve the desired results [12].

n) Low risk profile: This technology has no large-scale drug development risk since the toxicological profiles of the phytosomal components are well documented in the scientific literatures [13].

o) Relatively simple to manufacture with no complicated technical investment required for the production of Phytosomes.

\section{Disadvantage}

Phytoconstituent is rapidly eliminated from phytosome $[12,13]$.

\section{Selection of \\ Phytoconstituents/Formulation Considerations}

Following are selection criteria's of phytoconstituent from herbal extract for phytosomes preparation and formulation considerations for phytosome development.

\section{Selection of herbal extracts}

Herbal extracts posses various properties such as photo-protection, hepato-protection, anti-aging, moisturizing, and antioxidant, astringent, anti-irritant, and antimicrobial. Because of such properties they produces healing, softening, rejuvenating, and sunscreen effect on skin and improve pharmacological and pharmacokinetic profile in the body. After detailed literature survey of herbs and correlation of activity of herbal compounds based on chemical classes such as flavonoids, monoterpenes, polyphenols, indols and organosulfides, one can select herbal extracts on the basis of their nature, availability, estimation method, stability and utility of developed formulation as well as reported previous research.

\section{Nature of phytoconstituents}

Solubility is important criterion for the development of novel formulations. According to the nature of the phytoconstituents, that is hydrophilic or lipophilic, best suitable formulation can be selected.

\section{Selection of dosage form for delivery of phytosomes}

Suitable type of formulation/dosage form for delivery of phytosomes can be selected based on its potential for improving the effectiveness and efficiency of bioactive compound. The application of dosage form should improve its efficacy regarding continuous action of herbs on systemic effect of human body. The inherent properties of herbal drug such as hydrophilic or hydrophobic, surface characteristics of system such as permeability and charges, degree of biodegradability, and tonicity; release profile and size of the product required of the final formulation need to be taken in to consideration. Phytosome can be formulated for both oral as well as topical use. Following are few suggested dosage forms for phytosome delivery:

Soft gelatin capsules: The phytosome can be dispersed in oily vehicles (vegetable or semi-synthetic oil) to obtain suspension to be filled in soft gelatin capsules [12].

Hard gelatin capsules: Phytosomes can be filled in to hard gelatin capsules. A direct volumetric filling process without precompression (precompression might affect the disintegration time) can be applied. The low density of phytosome complex seems to limit the maximum amount of powder (usually not more than $300 \mathrm{mg}$ for size capsule) that can be filled into capsule. With the use of piston pump capsule filling process we can increase amount of powder to be filled in capsule [14].

Tablets: Due to limited flow ability, stickiness and low apparent density of phytosome complex, a direct compression process can be applied only for lower unitary doses. The phytosome complex should be diluted with $60-70 \%$ of excipients to obtain tablets with appropriate characteristics. Wet granulation should be avoided due to the negative effect of water and heat on stability of the phyto-phospholipid complex [12].

Topical dosage form: Firstly prepare emulsion at low temperature (not higher than $40^{\circ} \mathrm{C}$ ) after that incorporates the phytosome complex into it. The phyto-phospholipid complexes are dispersible in the main lipid solvents employed in topical formulation [15].

\section{Principle of Phytosome Technology}

The phytochemical constituents (flavonoids and terpenoides) of the extracts provide them for the direct complexation with Phosphatidylcholine. Phytosome results from the reaction of a stoichiometric amount of the phospholipid with the standardized extract or polyphenolic constituents in a non-polar solvent. The Phosphatidylcholine is a bi-functional compound composed of lipophilic phosphatidyl moiety and the hydrophilic choline moiety. The choline head of phosphatidylcholine molecule binds to phytocomponent while the lipid soluble phosphatidyl portion comprises the body and tail which then envelops the choline bound material. Hence, the Phytoconstituents build up a lipid compatible molecular complex with phospholipid also called as phyto-phospholipid complex [16].

\section{Properties of Phytosomes}

Following are some of the important properties of phytosomes:

\section{Physico-chemical properties}

a) Phytosome are prepared by reaction of stoichiometric amount of phospholipid with the standardized plant extracts as substrate. The spectroscopic data reveals that the phospholipid substrate interaction is due to the formation of hydrogen bond between the polar head (i.e., phosphate and ammonium group) and the polar functionalities of the substrate [17].

b) The size of Phytosome varies from $50 \mathrm{~nm}$ to a few hundred $\mu \mathrm{m}[18]$

c) Phytosome when treated with water assumes a micellar shape resembling liposome and photon correlation spectroscopy (PCS) reveals this liposomal structures acquired by phytosome [19]

d) The $\mathrm{H}^{1} \mathrm{NMR}$ and $\mathrm{C}^{13} \mathrm{NMR}$ data deduced that the fatty chain gives unchanged signals both in free phospholipid and in the complex, which indicates that long aliphatic chains are wrapped around the active principle producing lipophilic envelope [20].

e) The complexes are often freely soluble in aprotic solvents, moderately soluble in fats, insoluble in water and relatively unstable in alcohol. But the phytosomes of certain lipophilic phytoconstituents like curcumin has shown increase in water solubility upon complexation with phospholipid [21].

\section{Biological properties}

Phytosome are novel complexes which are better absorbed and utilized; hence they produce more bioavailability and better result than 
the conventional herbal extract or non-complex extracts, which has been demonstrated by pharmacokinetic studies or by pharmacodynamic tests in experimental animals and in human subjects [21].

\section{Preparation Methods of Phytosome}

Phytosome are novel complexes of herb extracts and lipids. Phytosome are formulated by the processes in which the standardized extract of active ingredients of herb are bound to phospholipid like phosphatidylcholine (PC), phosphatidylethanolamin or phosphatidylserine through a polar end [18]. Phytosome are prepared by reacting 3-2 moles of a natural or synthetic phospholipid with one mole of herbal extract. The reaction is carried out in aprotic solvent such as dioxane or acetone from which the complex can be isolated by precipitation with non solvent such as aliphatic hydrocarbons or lyophilization or by spray drying. In the complex formation of phytosome, the ratio between these two moieties range from 0.5-2.0 moles. The most preferably ratio of phospholipid to flavonoids is 1:1.The stepwise procedure of phytosome preparation is depicted in (Figure 1)

\section{Characterization and Evaluation of Phytosome}

Phytosomes are characterized for physical attributes, i.e. shape, size, its distribution, percentage drug capture, entrapped volume, percentage drug release, and chemical composition [18]. Hence, behavior of Phytosomes, in both physical and biological systems is governed by factors such as physical size, membrane permeability; percent entrapped solutes, chemical composition, quantity and purity of the starting material.

\section{Characterization techniques}

a) Visualization: Visualization of phytosomes can be achieved using transmission electron microscopy [4].

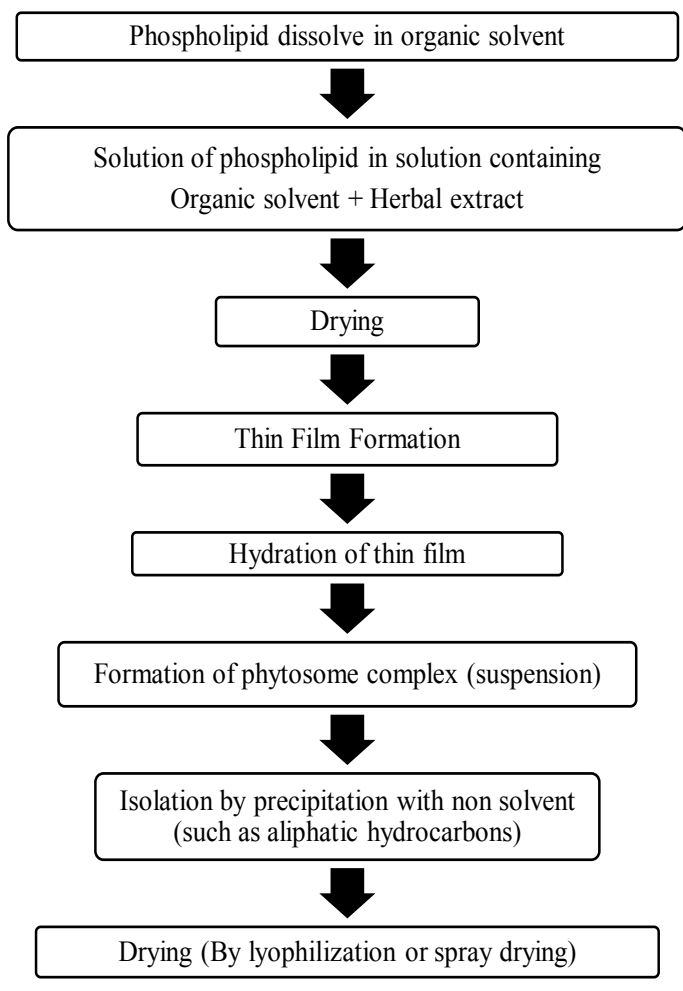

Figure 1: Flow diagram of Phytosome preparation. b) Entrapment efficiency: The entrapment efficient of a drug by phytosome can be measured by the ultracentrifugation technique [14]

c) Transition temperature: The transition temperature of the vesicular lipid systems can be determined by differential scanning colorimeter.

d) Surface tension activity measurement: The surface tension activity of the drug in aqueous solution can be measured by the ring method in a Du Nouy ring tensiometer [12].

e) Vesicle stability: The stability of vesicles can be determined by assessing the size and structure of the vesicles over time. The mean size is measured by Dynamic Light Scattering (DLS) and structural changes are monitored by Transmission Electron Microscopy (TEM) [17].

f) Drug content: The amount of drug can be quantified by modified high performance liquid chromatographic method or by a suitable spectroscopic method [13].

g) Vesicle size and Zeta potential: The particle size and zeta potential can be determine by DLS using a computerized inspection system and photon correlation spectroscopy [12].

\section{Spectroscopic evaluation}

To confirm the formation of a complex or to study the reciprocal interaction between the phytoconstituents and the phospholipid, the following spectroscopic methods are used.

a) $H^{1} N M R$ : In nonpolar solvents, there is a marked change of the ${ }^{1} \mathrm{H}$-NMR signal originating from the atoms involved in the formation of the complex, without any summation of the signal peculiar to the individual molecules. The signals from the protons belonging to the flavonoids are to be broadened that the proton cannot be relieved. In phospholipid, there is broadening of all the signals while the singlet corresponding to the $\mathrm{N}-\left(\mathrm{CH}_{3}\right)_{3}$ of choline undergo an uplift shift. Heating the sample to $60^{\circ} \mathrm{C}$ results in the appearance of some new broad bands, which correspond mainly to the resonance of the flavonoids moiety.

b) $\quad C^{13} N M R$ : The signals corresponding to the glycerol and choline portion of the lipid (between $60-80 \mathrm{ppm}$ ) are broadened and some are shifted, while most of the resonances of the fatty acid chains retain their original sharp line shape. After heating to $60^{\circ} \mathrm{C}$, all the signals belonging to the flavonoids moieties reappear, although they are still very broad and partially overlapping [11].

c) FTIR: The formation of the complex can be also be confirmed by IR spectroscopy by comparing the spectrum of the complex with the spectrum of the individual components and their mechanical mixtures. FTIR spectroscopy is also a useful tool for the control of the stability of phytosomes when micro-dispersed in water or when incorporated in very simple cosmetic gels. From a practical point of view, the stability can be confirmed by comparing the spectrum of the complex in solid form (phytosomes) with the spectrum of its micro dispersion in water after lyophilisation, at different times [18].

\section{In vitro and In vivo evaluations}

Models of in-vitro and in-vivo evaluations are selected on the basis of the expected therapeutic activity of biologically active phytoconstituents present in the phytosome. For example, in-vitro anti-hepatotoxic activity can be assessed by the antioxidant and free radical scavenging activity of phytosome. For assessing in vivo anti-hepatotoxic activity, 
the effect of prepared phytosomes on animals against thioacetamide, paracetamol or alcohol induced hepatotoxicity can be examined. Skin sensitization and tolerability studies of glycyrrhetinic acid phytosome ointment, a commercial product, describe the in-vivo safety evaluation methodology [18].

\section{Recent Researches on Phytosomes}

Numerous research works is being conducted by the researchers and the recent researches reveals that the phytosome technology is a novel method for improving the absorption and bioavailability of plant extracts significantly reducing the dose level. The suitability of this technique and increased demand of herbal medicines for various disease management in current scenario, has paved the way of newer researches [22]. The literature review on some current developments in phytosome formulations are discussed below:

Giorgi et al. [23] investigated the clinical usefulness of oral supplementation with a combination product containing alpha-lipoic acid, curcumin phytosome, and B group vitamins in 180 patients with carpal tunnel syndrome (CTS). The treatment was associated with high satisfaction levels and good compliance, suggesting the potential clinical usefulness of this supplementation before and after surgery in CTS patients scheduled for the surgical decompression of the median nerve.

Gianni et al. [24] evaluated the beneficial effects of Green select Phytosome, a proprietary lecithin formulation of a caffeine-free green tea catechin extract in a controlled registry study on 50 asymptomatic subjects borderline for metabolic syndrome factors and with increased plasma oxidative stress. Compared to the control (lifestyle and dietary change salone), Green select Phytosome was especially effective for weight/waist changes. The results highlighted the relevance of addressing multiple factors involved in the development of metabolic syndrome with apheliotropic agent capable of improving the beneficial effects of lifestyle and dietary changes and foster the attainment of a globally improved health profile.

Zaveri et al. [25] have prepared the curcumin-phospholipid complex in a molar ratio of (1:2) of curcumin and phospholipid. They confirmed the formation of complex by FT-IR Spectroscopy and DSC analysis. They compared the skin permeation of curcumin with the complexed curcumin and found that the complexed curcumin showed $60 \%$ greater permeation of curcumin through rat skin. They reported that the phospholipid complex has more transdermal penetration than pure curcumin.

Cuomo et al. [26] investigated the relative absorption of a standardized curcuminoid mixture and its corresponding lecithin formulation (Meriva) in a randomized, double blind cross over design human study. They reported the improved absorption and a better plasma curcuminoid profile of the Meriva at a dose significantly lower than unformulated curcuminoid mixture.

Gupta, Dixit [27] reported that incorporation of high amount of curcumin in topical formulation cannot provide a better bioavailability. They prepared complex of curcumin with phosphatidylcholine and characterized them on the basis of TLC, DSC, Melting point and FTIR. They compared the activity of vesicular systems like liposome, niosome, phyto-vesicle. In result they got that the phyto-vesicle are having excellent antioxidant and anti-aging properties than the other vesicular systems that may be due to the amphiphilic nature of the complex, which greatly enhances the water and lipid miscibility of the curcumin
Cao et al. [28] formulated Oxymatrine-phospholipid complex (OMT-PLC) to improve the lipid solubility and effectiveness of OMT. The purpose of their study was to explore the utility of the combination of a microemulsion and an OMT-PLC as topical delivery vehicle for enhancing the absorption and efficacy of OMT. They evaluated various physicochemical properties and in vitro and in vitro permeability through skin. They concluded that the combination of a microemulsion and phospholipid complex represents an effective vehicle for topical delivery of OMT.

Forster et al. [29] reported in there review that the topical delivery of plant derived products can be effectively done in cosmetic preparation by phospholipid complexation.

Kid [30] reported the hydration of the superficial corneous layer is related to the liposomal like properties of the phospholipid of the complex. Gingkoselect phytosomes possess a transdermal action which helps the ginseng saponin present in the phospholipid complex to penetrate into the skin.

Yanyu et al. [31] prepared the silymarin phytosome and studied its pharmacokinetics in rats. In this study, the bioavailability of silybin in rats was increased remarkably after oral administration of prepared silybin phospholipid complex due to an impressive improvement of the lipophilic property of silybin-phospholipid complex and improvement of the biological effect of silybin.

Maiti et al. [32] developed the Quercetin-phospholipid complex by a simple and reproducible method and also showed that the formulation exerted better therapeutic efficacy than the molecule in rat liver injury induced by carbon tetrachloride.

Busby et al. [33] reported that the use of a silymarin phytosome showed a better photoprotectant activity from ethanol-induced behavioural deficits than uncomplexed silymarin.

Grange et al. [34] conducted a series of studies on silymarin phytosome, containing a standardized extract from the seeds of $\mathrm{S}$. marianum, administered orally and found that it could protect the foetus from maternally ingested ethanol.

Moscarella et al. [35] investigated in one study of 232 patients with chronic hepatitis (viral, alcohol or drug induced) treated with silybin phytosome at a dose of $120 \mathrm{mg}$ either twice daily or thrice daily for up to 120 days, liver function returned to normal faster in patients taking silybin phytosome compared to a group of controls (49 treated with commercially available silymarin, 117 untreated or given placebo).

Bombardelli et al. [36] reported Silymarin phytosomes, in which Silymarin (A standardized mixture of flavanolignans extracted from the fruits of S. marianum) was complexed with phospholipid. Phytosomes showed much higher specific activity and a longer lasting action than the single components, with respect to per cent reduction of oedema, inhibition of myeloperoxidase activity, antioxidant and free radical scavenging properties.

\section{Commercial Products and Patents on Phytosomes}

To examine the various advantages of phytosomes, especially their ability to enhance the bioavailability of polar phytoconstituents, various therapeutic applications of phytosomes have been explored. The commercial products available in market and some patents on phytosome are listed below in (Tables 3 and 4) respectively. 
Citation: Pawar HA, Bhangale BD (2015) Phytosome as a Novel Biomedicine: A Microencapsulated Drug Delivery System. J Bioanal Biomed 7: 006012. doi:10.4172/1948-593X.1000116

\begin{tabular}{|c|c|c|c|}
\hline Sr. No. & Trade name & Phytoconstituents complex & Indications \\
\hline 1 & Silybin phytosome & Silybin from Silibium marianum & Hepatoprotective, Antioxidant. \\
\hline 2 & Grape seed (Leucoselect) phytosome & Procyanidins from vitis vinifera & Antioxidant, Anticancer. \\
\hline 3 & Ginseng phytosome & Ginsenosides from Panax ginseng & Immunomodulator \\
\hline 4 & Hawthorn phytosome & Flavonoids from Crataegus species & Antihypertensive, Cardioprotective. \\
\hline 5 & Sericoside phytosome & Sericoside from Terminalia sericea & Skin improver, Anti-Wrinkles \\
\hline 6 & Ginko select phytosome & Flavonoids from Ginko biloba & Anti aging,Protects Brain and Vascular liling \\
\hline 7 & Olea select phytosome & Polyphenols from Olea europea & Anti-hyperlipidemic, Anti-inflammatory \\
\hline 8 & Green select phytosome & Epigallocatechin from Thea sinensis & Anti-cancer, Antioxidant \\
\hline 9 & Echinacea phytosome & Echinacosides from Echinacea angustifolia & Immunomodulatory, Nutraceuticals. \\
\hline 10 & Bilberry (Mertoselect) phytosome & Anthocyanosides from Vaccinium myritillus & Antioxidant, Improvement of Capillary Tone. \\
\hline 11 & Palmetto (Sabalselect) phytosome & Fattyacids, alcohols and sterols from Serenoa repens & Anti-oxidant, Benign Prostatic hyperplasia. \\
\hline 12 & Visnadine (Visnadax) phytosome & Visnadine from Ammi visnaga & Circulation Improver, Vasokinetic \\
\hline 13 & Centella phytosome & Terpens from Centella asitica & Brain tonic, Vein and Skin Disorder \\
\hline 14 & Glycyrrhiza phytosome & $18-\beta$ glycyrrhetinic acid from Glycyrrhiza glabra & Anti-inflammatory, Soothing \\
\hline 15 & Melilotus (Lymphaselect) phytosome & Triterpens from Melilotus officinalis & Hypotensive, Indicated in Insomnia \\
\hline 16 & Curcumin (Merivaselect) phytosomes & Polyphenol from Curcuma longa & Cancer Chemo preventive Agent \\
\hline 17 & Mertoselect phytosome & Polyphenols, Antcinoside from Vaccinium myrtilus & Antioxidant \\
\hline 18 & PA2 phytosome & Proanthocyanidin A2 from horse Chestnut bark & Anti-Wrinkles, UV protectant. \\
\hline 19 & Escin $\beta$ sitosterol phytosome & Escin $\beta$-sitosterol from horse Chestnut fruit & Anti-odema. \\
\hline 20 & Ximilene and ximen oil phytosome & Ximilene and ximen oil from Santalum album & Skin Smoothner, Micro Circulation Improver \\
\hline 21 & Ruscogenin phytosome & Steroid saponins from Ruscus aculeatus & Anti-inflammatory, Improve Skin circulation \\
\hline 22 & Zanthalene phytosome & Zanthalene from Zanthoxylum bungeanum & Soothing, Anti-Irritant, Anti-Itching \\
\hline 23 & Curbilene phytosome & Curbilene from Curcurbita pepo seeds & Skin care, Matting Agent \\
\hline 24 & Esculoside phytosome & Esculoside from Aesculus hippocastannum & Vasoactiv, Anti-cellulite, Microcirculation improver \\
\hline
\end{tabular}

Table 3: Commercial products and their applications.

\section{Title of patent}

Phospholipid complexes of olive fruits or leaves

Compositions comprising Ginkgo biloba derivatives for the treatment of asthmatic and allergic conditions

Fatty acid monoesters of sorbityl furfural and compositions for cosmetic and dermatological us

Cosmetic and dermatological composition for the treatment of aging or photo damaged skin

Treatment of skin, and wound repair, with thymosin $\beta 4$ Soluble isoflavone compositions extracts having improved bioavailability

\section{Innovation}

Phospholipid complexes of olive fruits or leaves extracts or compositions containing it having improved bioavailability

Compositions containing fractions deriving from Ginkgo biloba, useful for the treatment of asthmatic and allergic conditions

Fatty acid monoesters of sorbityl furfural selected from two diff series EP1690862

\begin{tabular}{|l} 
Patent No \\
EP/1844785
\end{tabular}

EP1813280

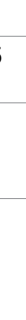

alkyl radical optionally conta least one ethylenic unsaturation

Composition for topical treatment of the skin comprises a substance that stimulates collagen synthesis and a substance that enhances the interaction between extracellular matrix and fibroblasts Cosmetic or dermatological composition for topical treatment

Compositions and methods for treatment of skin utilizing thymosin $\beta 4$. Isoflavone compositions exhibiting improved solubility (e.g., light transmittance), taste, colour, and texture characteristics, and methods for making the same

An anti-oxidant preparation based on plant extracts Preparation based on plant extracts which has an anti-oxidant effect for the treatment of circulation and adiposity and is particularly useful in treatment of circulation problems such as problems

Complexes of saponins with phospholipid and pharmaceutical and cosmetic compositions containing them phlebitis, varicosevein, arteriosclerosis, haemorrhoid and high blood pressure.

Complexes of saponins with natural or synthetic phospholipid have high lipophilic and improved bioavailability and are suitable for use as active principle in pharmaceutical, dermatologic and cosmetic

EP1640041

\author{
C
} compositions

\begin{tabular}{|l|l|}
\hline US/2007/ 0015698 & {$[40]$} \\
\hline WO/2004/ 045541 & {$[41]$} \\
\hline EP1214084 & {$[42]$} \\
\hline EP0283713 & \\
\hline
\end{tabular}

Table 4: Patented technologies of phytosome.

\section{Conclusion}

Phytosome are advanced form of herbal extract that are absorbed better than conventional herbal extract. The article thus reviews the benefits, physical characteristics, chemical properties, and method of preparation of phytosomes. The formulation methodology for phytosome is simple and can be easily upgraded to a commercial scale. These are novel complexes showing much better absorption profile following oral administration owing to improved lipid solubility which enable them to cross the biological membrane, resulting in enhanced bioavailability i.e. more amount of active principle in the systemic circulation. Also phytosomes are superior to liposomes due to much better absorption and stability profile. As mentioned in the literature, phytosomes have been therapeutically used for hepatoprotective and liver diseases. After screening and selection of herbal extracts, one can develop Phytosomal drug delivery systems for various drug categories like anticancer, cardiovascular, and anti-inflammatory activities, etc. 
Citation: Pawar HA, Bhangale BD (2015) Phytosome as a Novel Biomedicine: A Microencapsulated Drug Delivery System. J Bioanal Biomed 7: 006012. doi:10.4172/1948-593X.1000116

\section{References}

1. Dhiman A, Nanda A, Ahmad S (2012) Novel Herbal Drug Delivery System (NHDDS): the need of Hour. International Conference on Environment, Chemistry and Biology 49: 171-175.

2. Gold J, Laxer D, Rochon P (2000) Herbal remedies; a critical perspective. Ann R Coll Physician Surg Can 33: 497-498

3. Gupta A, Ashawal MS, Saraf S (2007) Phytosome: a novel approach towards functional cosmetics. J Plant Science. 644-649.

4. Kumari $P$, Singh N, Cheriyan $P$, Neelam (2011) Phytosome: a noval approach for phytomedicine. International Journal of Institutional Pharmacy and Life Sciences. 1: 89-100.

5. Kareparamban J, Nikam P, Jadhav A, Kadam V (2012) Phytosome: a novel revolution in herbal drugs. International journal of research in pharmacy and chemistry 2: 299-310

6. Gupta S, Singh RP, Lokwani P, Yadav S, Gupta SK (2011) Vesicular system as targeted drug delivery system: an overview. Int J Pharm Tech 3: 987-1021.

7. Rathore P (2012) Planterosomes: potential phyto-phospholipid carriers for the bioavailability enhancement of herbal extracts. International journal of pharmaceutical science and research 3: 737-755

8. Valenzuela A, Aspillaga M, Vial S, Guerra R (1989) Selectivity of silymarin on the increase of the glutathione content in different tissues of the rat. Planta Med 55: 420-422.

9. Saraf S, Kaur CD (2010) Phytoconstituents as photoprotective novel cosmetic formulations. Pharmacogn Rev 4: 1-11.

10. Pandey S (2010) Phytosome: Technical Revolution in Phytomedicine International Journal of PharmTech Research 2: 627-631.

11. Amin T, Bhat S (2012) A Review on Phytosome Technology as a Novel Approach to Improve the Bioavailability of Neutraceuticals. International Journal of Advancements in Research and Technology 1: 1-15.

12. Saha S, Sarma A, Saikia P, Chakrabarty T (2013) Phytosome: A Brief Overview Scholars Academic Journal of Pharmacy 2: 12-20.

13. Battacharya S (2009) Phytosome: Emerging strategy in delivery of herbal drugs and nutraceuticals. PharmTimes 41: 3

14. Varde N, Mehta N, Thakor N, Shah V, Upadhyay U (2012) Phytosomes: a potential phospholipid nanoparticulate carrier for the bioavailability enhancement of herbal extracts. International journal of comprehensive pharmacy 10: 1-7.

15. El Maghraby GM, Williams AC, Barry BW (2000) Oestradiol skin delivery from ultradeformable liposomes: refinement of surfactant concentration. Int J Pharm 196: 63-74.

16. Comoglio A, Tomasi A, Malandrino S, Poli G, Albano E (1995) Scavenging effect of silipide, a new silybin-phospholipid complex, on ethanol-derived free radicals. Biochem Pharmacol 50: 1313-1316.

17. Tripathy S, Patel D, Baro L, Nair S (2013) A review on phytosomes, their characterization, advancement and potential for transdermal application, Journal of Drug Delivery and Therapeutics 3:147-152.

18. Patel A, Tanwar Y, Rakesh S, Patel P (2013) Phytosome: Phytolipid Drug Delivery System for Improving Bioavailability of Herbal Drug. Journal of Pharmaceutical Science and Bio scientific Research 3: 51-57.

19. Jain NK (2005) Liposomes as drug carriers, controlled and novel drug delivery, 1 st edition, CBS publisher 321-326

20. Dayan N, Touitou E (2000) Carriers for skin delivery of trihexyphenidyl $\mathrm{HCl}$ : ethosomes vs. liposomes. Biomaterials 21: 1879-1885.

21. Maffei Facino R, Carini M, Aldini G, Bombardelli E, Morazzoni $P$, et al. (1994) Free radicals scavenging action and anti-enzyme activities of procyanidines from Vitis vinifera. A mechanism for their capillary protective action. Arzneimittelforschung 44: 592-601.

22. More M, shende M, kolhe D, Jaiswal N (2012) Herbosomes: herbo-phospholipid complex an approach for absorption enhancement. International journal of biological and pharmaceutical research 3: 946-955.

23. Giorgio P, Paola B, Veronica P, Chiara N (2014) Clinical Usefulness of Oral Supplementation with Alpha-Lipoic Acid, Curcumin Phytosome, and B-Group
Vitamins in Patients with Carpal Tunnel Syndrome Undergoing Surgical Treatment. Evidence-Based Complementary and Alternative Medicine 1-7.

24. Gianni B, Andrea L, Shu H , Maria RC, Beatrice F, et al. (2013) Greenselect Phytosome for Borderline Metabolic Syndrome. Evidence-Based Complementary and Alternative Medicine 1-7.

25. Zaveri M, Gajjar H, Kanaki N, Patel S (2011) Preparation and evaluation of drug phospholipid complex for increasing transdermal penetration of phytoconstituents. International Journal of Institutional Pharmacy and Life sciences 1: 80-93.

26. Cuomo J, Appendino G, Dern AS, Schneider E, McKinnon TP, et al. (2011) Comparative absorption of a standardized curcuminoid mixture and its lecithin formulation. J Nat Prod 74: 664-669.

27. Gupta NK, Dixit VK (2011) Development and evaluation of vesicular system fo curcumin delivery. Arch Dermatol Res 303: 89-101.

28. Cao FH, OuYang WQ, Wang YP, Yue PF, Li SP (2011) A combination of microemulsion and a phospholipid complex for topical delivery of oxymatrine. Arch Pharm Res 34: 551-562.

29. Forster M, Bolzinger MA, Fessi H, Briançon S (2009) Topical delivery of cosmetics and drugs. Molecular aspects of percutaneous absorption and delivery. Eur J Dermatol 19: 309-323.

30. Kidd PM1 (2009) Bioavailability and activity of phytosome complexes from botanical polyphenols: the silymarin, curcumin, green tea, and grape seed extracts. Altern Med Rev 14: 226-246.

31. Yanyu X, Yunmei S, Zhipeng C, Qineng P (2006) The preparation of silybinphospholipid complex and the study on its pharmacokinetics in rats. Int $J$ Pharm 307: 77-82.

32. Maiti K, Mukherjee K, Gantait A, Ahamed HN, Saha BP, et al. (2005) Enhanced therapeutic benefit of quercetin-phospholipid complex in carbon tetrachloride induced acute liver injury in rats: a comparative study. Iranian Journal of Pharmacology and Therapeutics 4: 84-90.

33. Busby A, La Grange L, Edwards J, King J (2002) The use of a silymarin phospholipid compound as a fetoprotectant from ethanol-induced behavioral deficits. J Herb Pharmacother 2: 39-47.

34. La Grange L, Wang M, Watkins R, Ortiz D, Sanchez ME, et al. (1999) Protective effects of the flavonoid mixture, silymarin, on fetal rat brain and liver. J Ethnopharmacol 65: 53-61.

35. Mascarella S, Guisti A, Marra F, Marena C, Relli P, et al. (1992) Therapeutic and antilipoperoxidant effects of silybin phosphatidylcholine complex in chronic liver disease, Preliminary results. Current Therapeutic Research 53: 98-102.

36. Bombardelli E, Mustich G (1991) Bilobalide-phospholipid comlex, their uses and formulation containing them. U. S. Patent No. EPO-275005.

37. Doering T, Traeger A, Waldmann-Laue M (2006) Cosmetic and dermatologica composition for the treatment of aging or photodamaged skin. EP1640041.

38. Comoglio A, Tomasi A, Malandrino S, Poli G, Albano E (1995) Scavenging effect of silipide-A new silybin-phospholipid complex on ethanol derived free radicals, Biochem. Pharmacol 50: 1313-1316.

39. Cevc G, Schatzlein A, Blume G (1995) Transdermal Drug Carriers: Basic Properties,Optimization and Transfer Efficiency in Case of Epicutaneously Applied Peptides. J.Control Release. 36: 3-16.

40. S Battacharya (2009) Phytosome: Emerging strategy in delivery of herbal drugs and nutraceuticals. PharmTimes 41: 3.

41. Chauhan NS, Gowtham R, Gopalkrishna B (2009) Phytosome: Apotentia phyto-phospholipid carriers for herbal drug delivery. J. Pharm Res 2: 1267-1270.

42. Maghraby GM, Williams EC, Barry BW (2000) Oestradiol skin delivery from ultradeformable liposomes: refinement of surfactant concentration. Int J.Pharm. 196: 63-74.

43. Fry DW, White JC, Goldman ID (1978) Rapid Sectretion of Low Molecula Weight Solute from Liposomes without Dilution. Anal.Biochem 90: 809-815. 